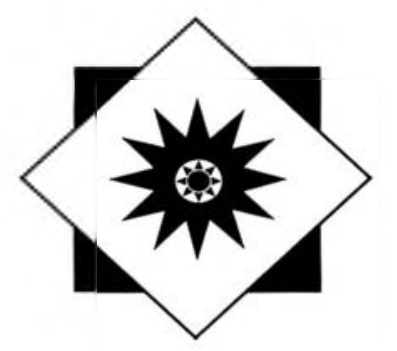

\title{
INNOVATIONS
}

\section{Making term paper counseling more meaningful}

\author{
By Kwasi Sarkodie-Mensah \\ Bibliographic Instruction Coordinator \\ Northeastern University
}

Many libraries have special sessions at the end of the semester when students are asked to come into the library for assistance on their term paper projects. The rationale behind such sessions includes providing better, and more personalized assistance to the students as they struggle to start or finish the given assignment for the semester. One can say that in their day-to-day activities, librarians provide term paper counseling in the sense that they help the students indirectly on the best approach to complete their papers. However, term paper counseling is unique in the sense that students are provided the unique opportunity to consult with librarians on a one-to-one basis, and for longer periods than they would spend with librarians at the reference desk. Usually, unless there are extra staff members to help out with the heavy circulation caused by enthusiastic responses to term paper counseling announcement, the reference desk can be an avenue of disaster, and the effectiveness of the programs can be drastically reduced. A clear example is the experience at the Morisset Library, Ottawa, Canada, when "on the last few days [of end of semester term paper counseling sessions], some students had to be turned away."

At Xavier University of Louisiana, New Orleans, the reference library has experimented with various term paper counseling techniques which, judging from the reactions of faculty members and students, have eased the burden of last-minute

'T. Schobert, "Term Paper Counseling: Individualizing Bibliographic Instruction," $R Q 22$ (Winter 1982): 146. anxiety over completion of the papers, not to mention the improvement of the quality of the papers. The following is a description of our experience at Xavier, as well as the rationale behind the techniques we explored.

Term paper counseling is a semester-long process. Course outlines given to students at the beginning of the semester clearly indicate the responsibilities of the students in their various classes. Thus, those whose classes require a term paper learn about such an obligation in the early part of the semester. Most students are in the habit of waiting until a few days before the term papers are due to start working on these projects. Students coming to the library a few hours before term papers are due is not an uncommon sight. Our practice is to send out notices as early in the semester as possible, urging students to start thinking about their term papers, and to come into the library for all the assistance they may require. The word "all" is used to entice the students, but as they come in, they are told what they can expect from the sessions.

Sample notices. At least four notices are sent in the semester. Thanks to our old, but still somewhat useful, version of the Printmaster program, we can generate a page-long notice, using appropriate graphics-masks for Mardi Gras, pumpkins for Halloween, turkeys for Thanksgiving, for example-and reproduce them on the photocopy machines, so that we can saturate the campus with them. Our first notice is usually like this: "It's not too early to start thinking about those term papers. Come to the library for all the assistance you may require."

Naturally, this does not send in a flock of stu- 
dents to the library, most probably because an early start on a term paper takes some of the fun out of the frenzy that accompanies the completion of projects under pressure. However, a considerable number of students wander in, asking for assistance in an almost apologetic mood: "My paper is not due till the end of April, but I want to get an early start on it." Others, however are not bashful to admit that they came in response to the notices on campus.

The second notice, which goes out around midterms, reads as follows: "Be smart. Start working on your term paper(s) today!!! The reference librarians are ready to assist you. Come to the reference room today. No appointment necessary."

The inclusion of the last statement is to get the students into the library. After the initial meetings, various times are arranged with them as they start on their term papers. (If you are familiar with the oldest version of Printmaster, you know all this will not fit on one screen. Well, we do two screens, and then reduce it on the photocopy machine from 8 by 17 to 8 by 11). The number of students answering this notice is significantly higher than those showing up after the first. The reasons? Some of the fun of the semester has already eroded. Add and drop are nothing but labels that became hard-to-accept realities, and students remaining in their classes fall into various categories: those who love them; those who cannot afford to drop, or let their courses drop by any means; and those who can drop, but tired of the constant and systematic maneuvers of drop and add, have exhausted all the means of escaping the realities of college graduation requirements. Courses that are hated have to be taken for the students to become diploma-bearing members of the pack. To be on the fair side, it is proper to say that many students responding to the second call are genuinely interested in getting an earlier start on their papers.

Two weeks after midterms, students begin to sense the end of the semester. They suddenly become concerned about completing their end of term projects, and at the same time devise strategies of combining term papers and studying for final examinations. This is the best time to send more notices about term paper counseling. The tone of the notices can be heightened to reflect both anxiety and hope. At the third notice, the library should be prepared for heavier traffic because that is the period when your message is most likely to sink very deeply in the minds of your students. Unlike those few days after course outlines were handed to them, and you tried to get them to work, these last weeks are closer to deadlines, and do not compromise very well with postponement. A message such as this will be taken to heart: "Have a peaceful end of semester. Start working on those term papers today. Come to the library for all the assistance you may need." The traffic to the library is likely to increase, but thanks to the two previous campaigns, it will not be all the students on the registrar's list who will troop to the library. There still will be a huge number of students, but those who came in after the first and second waves may have been making progress on their papers by now.

The final notice comes in various forms. Whatever form is chosen, proper graphics must be used. We have used running shoes for the notice that reads: "Stuck on your term paper(s)? Don't worry; be snappy. Run to the library now!!!" The overtime graphics also work perfectly for the final notices. The heaviest traffic occurs after the last notices go out, but at this time there will be fewer students, since some of the students who might have joined the last flock would have come in after the previous notices.

Faculty involvement. At every stage of the term paper counseling campaign, faculty members are informed about the library's program. Letters are sent to departmental heads so that they would pass on the message to their department members. It is cheaper to send a note to each head of department than to individual faculty members. Faculty members are asked to encourage their students to take advantage of the term paper counseling sessions.

What is covered? The needs of the students will dictate the nature of term paper counseling, but usually this is an excellent opportunity to run through the process of finding information. The Arp and Wilson three-step research strategy has proven effective on many occasions, with the appropriate modification. ${ }^{2}$ The students can be introduced to the general reference sources in their disciplines for background information to their topics. The bibliographies at the end of some of the articles can always be used by the students to locate further information. Books available on the topic are pinpointed through the use of the card catalog. Indexes and abstracts and the availability of online searches are also highlighted so that the students become aware of the existence of specific tools in their area of research, instead of them falling on the Readers' Guide, and/or Infotrac for everything they need.

It is always important to show the students how to locate the periodical titles owned by the library, or by other libraries in the area. The possibility of the required article being on microform should also be emphasized, and assurances given that help in using the microform readers is readily available. Many students tend to walk out of the library to

${ }^{2}$ Lori Arp and Lizabeth A. Wilson, "Library Instructors' View: Theoretical [and Practical]," Research Strategies 2 (Winter 1984): 16-32. 
conceal their embarrassment in asking a library staff person to show them how to use microforms. And there are those students whose favorite hit tune, "I hate microfiche," is played any time you mention that the New York Times is on microfilm. For such students, calming their fears, and showing them how easy it is to use such information media works wonders. Once they escape from being bitten by the machines, they may never become shy to ask to be taught to or even dare use microforms.

Finding the appropriate style manual to organize bibliographies and references can also be a source of frustration for the students. For this reason, including style manuals in the counseling sessions can be profitable. Students are encouraged to look at a few of those titles, and familiarize themselves with the ones required by their teachers.

Even though typing facilities may not be considered part of term paper counseling, a knowledge of the existence of such services on the part of the librarian can be helpful. The students can become aware of those as early as possible, and those students who are moved by your overwhelming assistance will not come to you asking you to type their papers for them. Many computer centers on college campuses provide opportunities for students desirous of learning word processing programs that will help them type their papers.
One might question the rationale behind these aggressive attempts on the part of the library to get students complete their term papers on time, or even before the papers are due.

We feel that the library has an inseparable role in the education of the students. Even though some students often see term papers as tedious assignments that have to be turned in for grades, we in the library feel that the term paper project is an excellent preparation for the students for present and future research work. Students who take term paper assignments seriously and go through the systematic but painful procedure of gathering information are being trained in the area of research, and to be on their own in any type of library.

At Xavier we have never taken pride in hearing the sermon from some students and faculty that the library never has anything they need. However, we take delight in the fact that even the most prosperous library has to depend on other libraries for some of the materials their patrons need. Research work sometimes involves obtaining unavailable materials from other libraries. The earlier term paper counseling sessions are held, the more accustomed students become with the fact that interlibrary loan may take days or weeks for delivery, as opposed to a matter of hours. This is not in any way to challenge the wonders of fax, but realizing the implications and costs of fax, we believe that a re-

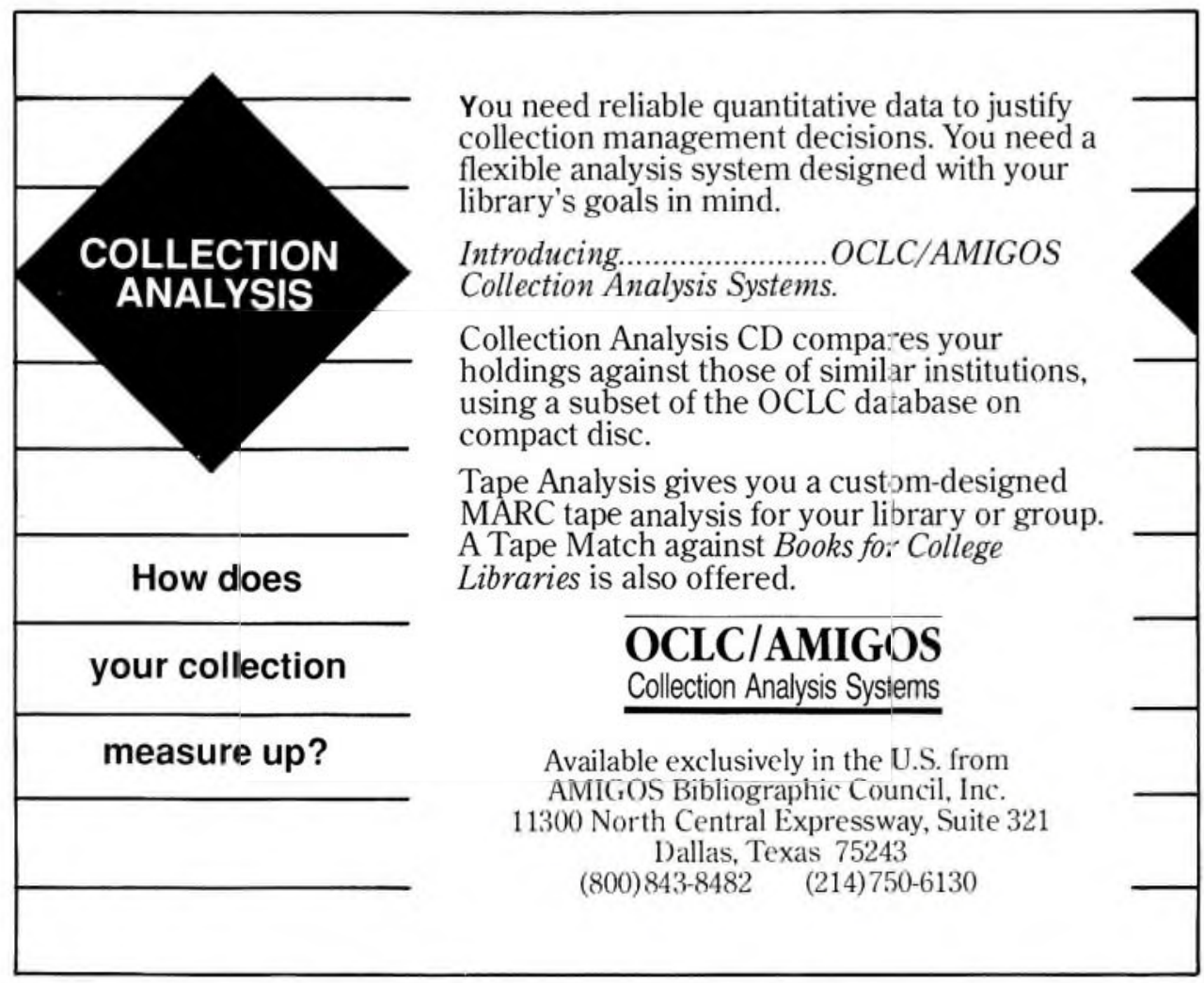


search work started well in time can produce a better end product than one started at the last minute. Students are able to understand the turnaround time of obtaining materials that are not readily available. In addition, students will be able to devote the end of the semester to reviewing their materials for final examinations, rather than combining the pressure of turning in a paper with the tedious process of getting ready for examinations.

Term paper counseling sessions are very useful to the students we deal with. However, unless these sessions are started early enough in and continued throughout the semester, the laudable intentions of librarians can be thwarted as a result of congestion at the reference desk during the last days of the semester. Our semester-long term paper counseling sessions have brought peace and quiet to the reference desk at the end of the semester. However, as one could have guessed, there are still many students who will never subscribe to our concept of early start on their papers. They still come in at the last minute, filled with anxiety, armed with impatience, and ready to negotiate for extended library hours to be able to finish their papers on schedule.

\section{Humor and creativity: MLS envy}

\author{
By J. C. Bennett
}

\author{
Assistant Professor of Library Science \\ Eastern New Mexico University
}

In any field, subordinates who feel that they can capably perform the work of their superiors may create difficulties. In libraries, paraprofessionals cause severe logical dilemmas for professional librarians when they espouse this feeling, herein termed "MLS envy." MLS envy is a stage of the paraprofessional's development into a loyal, hardworking flunky. Avoiding it requires that paraprofessionals be made to feel more positive about their inability to rise above a trivial rank. Like all psychological phases, MLS envy must be resolved before paraprofessionals can be said to be fully mature. They must be willing to accept the second-class status their position entails.

MLS envy requires careful handling. It usually sets in between one and eight weeks after the new paraprofessional begins work. The complex proceeds gradually. At first, subjects foolishly believe that they have intentionally been given their department's most monotonous tasks and that they have little hope of quickly moving on to more interesting assignments. Subjects may irrationally assume that older, more experienced paraprofessionals must perform tasks only slightly less tedious than their own. MLS envy is well on its way when subjects feel that they are being treated unjustly by being paid half or less of the starting professional's salary, even though the professionals in question may be younger than the nonprofessionals, hold fewer degrees, and have less employment experience. The complex is full blown when subjects become convinced that they could competently perform professional work without the benefit of an MLS degree.

The symptoms are generally easy to detect. In the early stages subjects are restless and uneasy, doubt the wisdom of superiors, and may feel disenchanted with their work. Such feelings become stronger as time passes, until the complex is truly visited on them. At that point, deep problems arise. Subjects may become bitter, insolent, lazy, and unmanageable; they may harbor thoughts of quitting without notice; they may be habitually absent or unbearably late with only poor excuses. Through all this they deserve sympathy and mercy, and a strong hand to guide and lead them along a path of reason and sense.

To move forward, resolution of the internal conflict is necessary. If subjects are to live happy, contented lives as paraprofessionals, they must believe in their supervisors and trust them to do what is best, no matter how painful it may be. If, after a grace period of several weeks after the onset of erroneous thoughts, subjects are unwilling or unable to submit completely, they are unlikely to progress very far, and will stay fixated at an irrational stage for the rest of their paraprofessional careers. Their superiors will then be wise to seriously consider terminating them with the merciful hope that they will prostrate themselves more readily in another field. If the superiors decide not to do so, they must be willing to work closely with sub- 